\title{
Validation of IMERG Precipitation in Africa
}

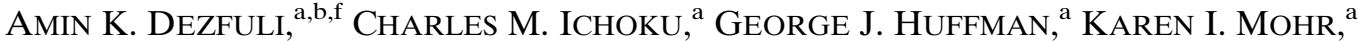 \\ JOHN S. SELKER, ${ }^{\mathrm{c}}$ NiCK VAN DE GIESEN, ${ }^{\mathrm{d}}$ REBECCA HOCHREUTENER,${ }^{\mathrm{c}}$ AND FrANK O. ANNOR ${ }^{\mathrm{d}, \mathrm{e}}$ \\ ${ }^{\text {a }}$ NASA Goddard Space Flight Center, Greenbelt, Maryland \\ ${ }^{\mathrm{b}}$ Universities Space Research Association, Columbia, Maryland \\ ${ }^{\mathrm{c}}$ Biological and Ecological Engineering, Oregon State University, Corvallis, Oregon \\ ${ }^{\mathrm{d}}$ Faculty of Civil Engineering and Geosciences, Delft University of Technology, Delft, Netherlands \\ ${ }^{\mathrm{e}}$ Department of Civil Engineering, Kwame Nkrumah University of Science and Technology, Kumasi, Ghana
}

(Manuscript received 21 July 2017, in final form 11 September 2017)

\begin{abstract}
Understanding of hydroclimatic processes in Africa has been hindered by the lack of in situ precipitation measurements. Satellite-based observations, in particular, the TRMM Multisatellite Precipitation Analysis (TMPA) have been pivotal to filling this void. The recently released Integrated Multisatellite Retrievals for GPM (IMERG) project aims to continue the legacy of its predecessor, TMPA, and provide higher-resolution data. Here, IMERG-V04A precipitation data are validated using in situ observations from the Trans-African HydroMeteorological Observatory (TAHMO) project. Various evaluation measures are examined over a select number of stations in West and East Africa. In addition, continent-wide comparisons are made between IMERG and TMPA. The results show that the performance of the satellite-based products varies by season, region, and the evaluation statistics. The precipitation diurnal cycle is relatively better captured by IMERG than TMPA. Both products exhibit a better agreement with gauge data in East Africa and humid West Africa than in the southern Sahel. However, a clear advantage for IMERG is not apparent in detecting the annual cycle. Although all gridded products used here reasonably capture the annual cycle, some differences are evident during the short rains in East Africa. Direct comparison between IMERG and TMPA over the entire continent reveals that the similarity between the two products is also regionally heterogeneous. Except for Zimbabwe and Madagascar, where both satellite-based observations present a good agreement, the two products generally have their largest differences over mountainous regions. IMERG seems to have achieved a reduction in the positive bias evident in TMPA over Lake Victoria.
\end{abstract}

\section{Introduction}

Our knowledge about rainfall characteristics in Africa has been hampered by the lack of in situ observations. (Fig. 1a and Fig. S1 in the supplemental material). This is caused by a number of factors, including restricted datasharing policies and poor infrastructure due to economic vulnerability and long-lasting regional conflicts. Satellitebased precipitation observations have served as an alternative to fill this void, though insufficient ground-based

Supplemental information related to this paper is available at the Journals Online website: https://doi.org/10.1175/ JHM-D-17-0139.s1.

${ }^{\mathrm{f}}$ Current affiliations: Science Systems and Applications, Inc, Lanham, and NASA Global Modeling and Assimilation Office, Greenbelt, Maryland.

Corresponding author: Amin K. Dezfuli, amin.dezfuli@nasa.gov rainfall records for calibration have posed some concerns for using these datasets. The TRMM Multisatellite Precipitation Analysis (TMPA), in particular, has been successfully used in numerous studies (e.g., Beighley et al. 2011; Naumann et al. 2012; Dezfuli and Nicholson 2013; Munzimi et al. 2015; Ichoku et al. 2016). Built upon that success, the Global Precipitation Measurement (GPM) mission has been recently released by NASA and JAXA as a global successor to the TRMM project (Huffman et al. 2015). The Integrated Multisatellite Retrievals for GPM (IMERG), which incorporates observations from several satellites, offers improvements over the TMPA in quality and spatiotemporal resolution of precipitation data (e.g., Ma et al. 2016; Prakash et al. 2016; Sharifi et al. 2016; Tang et al. 2016a). This is critical for enhancing our knowledge about various climatic phenomena in Africa that, in addition to their regional implications, have significant contributions to the global climate system (e.g., Swap et al. 1992; Kiladis et al. 2006; Dezfuli and Nicholson 2011; 

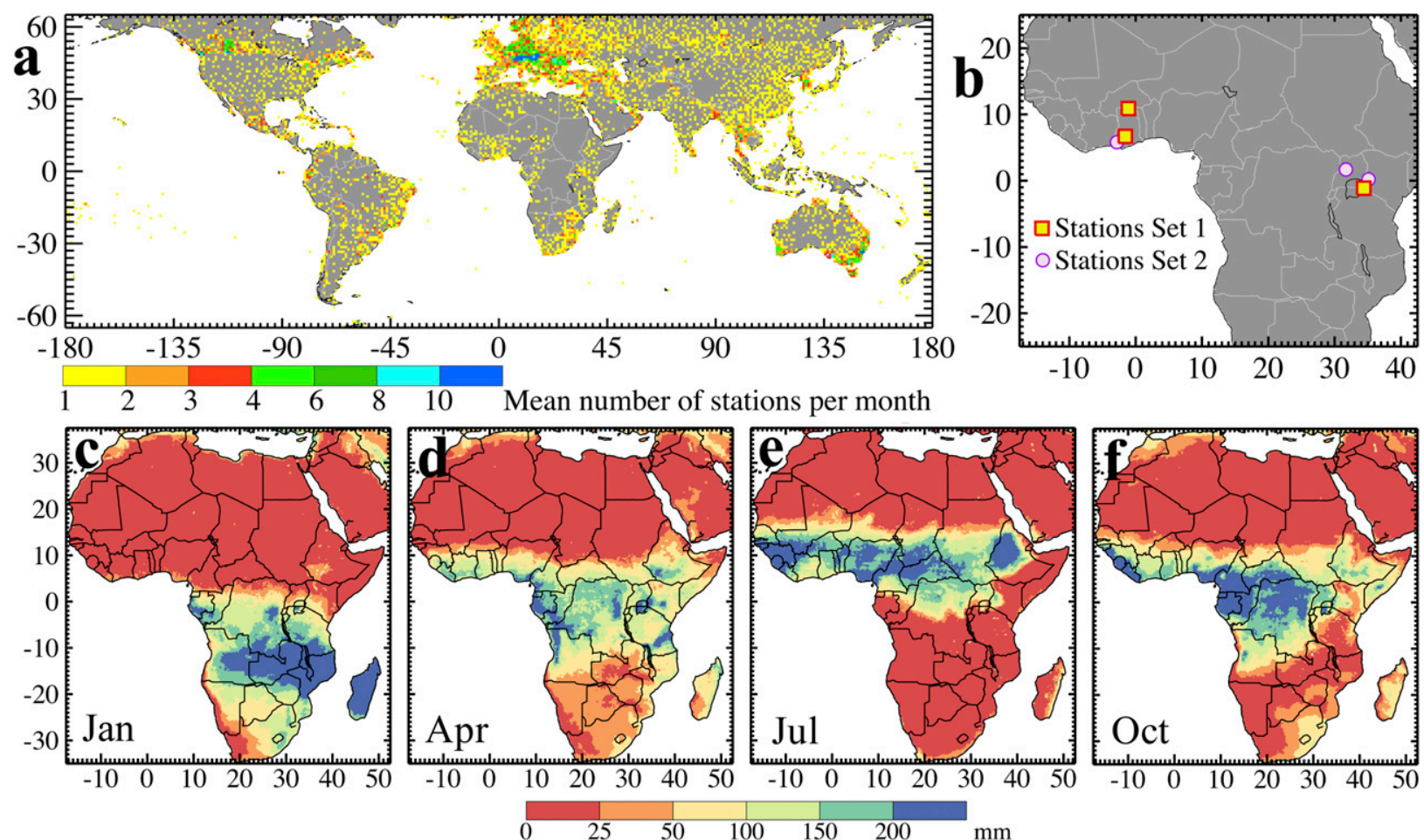

FIG. 1. (a) Mean number of stations per month used in the GPCC First Guess Daily product during 2015. (b) Location of the TAHMO weather stations. For Stations Set 1, the annual cycle, diurnal cycle, and PDF of daily rainfall are examined. For Stations Set 2, only the diurnal cycle is examined. (c)-(f) Long-term mean (1998-2015) patterns of monthly precipitation using TMPA 3B42 data.

Lawrence and Vandecar 2015; Rivero-Calle et al. 2016). Performance of various aspects of the IMERG precipitation has been examined in different regions of the world (e.g., Liu 2016; Oliveira et al. 2016; Tan et al. 2016; Tang et al. 2016b; Asong et al. 2017). Such literature, however, is limited for Africa, primarily due to the lack of in situ records (Hill et al. 2016; Sahlu et al. 2016; Dezfuli et al. 2017).

In this paper, we validate the half-hourly IMERG-V04A precipitation, using several weather stations in tropical Africa with very high temporal resolution. The diurnal variability, annual cycle, and frequency distribution of rain events from IMERG are compared with in situ and several gridded precipitation products. These include TMPA, for which the intercomparison is performed on the spatial patterns of various evaluation measures over the entire continent of Africa. This study serves as a followup to our recent work (Dezfuli et al. 2017), in which the same in situ data along with the IMERG and TMPA observations have been used to examine the characteristics of rain-producing systems in tropical Africa.

\section{Precipitation data}

Various precipitation datasets are analyzed in order to have a comprehensive representation of the major types of available products that are cited in the literature. These include five different datasets, obtained from a set of individual stations and four gridded products. Of these four, two are satellite-based (TMPA and IMERG), one is gauge-based (GPCC), and one is a blended gaugesatellite product [Climate Hazards Group Infrared Precipitation with Stations (CHIRPS)].

The in situ data are provided by the Trans-African Hydro-Meteorological Observatory (TAHMO). This recent initiative currently consists of about 100 low-cost weather stations, mainly in West and East Africa, and plans to grow its network to 20000 stations across the entire continent (Van de Giesen et al. 2014). The TAHMO stations measure the standard meteorological variables at 5-min intervals. Most stations, however, have data over a short period or are currently under quality control. We have selected three stations that met the quality control criteria and have data over the entire or most of the rainy season of 2015 (Fig. 1b): Lela Primary School (LPS) in Kenya and Kumasi and Navrongo in southern and northern Ghana, respectively. Three additional stations with a limited data period are also used only for analysis of diurnal variability. The stations are located within equatorial Africa, where the meridional excursion of the tropical rain belt creates a strong annual cycle of rainfall (Figs. 1c-f; Dezfuli 2017). 
The TMPA and IMERG data have been accessed from the NASA Precipitation Measurement Missions web portal (https://pmm.nasa.gov/). The TMPA-3B42 (V7) product used here is available at daily and three hourly intervals and $0.25^{\circ}$ spatial resolution. The IMERG product, which serves as the successor of TMPA, has a half-hourly temporal and $0.1^{\circ}$ spatial resolution. The "Final Run" product of IMERG-V04A, which is calibrated with the GPCC gauge analysis, has been utilized. The GPCC First Guess Daily Product, available at $1^{\circ}$ grid resolution (Schamm et al. 2014), is also used for data comparisons. This product incorporates precipitation records from weather stations across the globe (Figs. 1a, S1), collected via the Global Telecommunication System (GTS). The CHIRPS data are used as the representative of the merged gauge-satellite products because of their high resolution, low bias, and good gauge coverage over Africa compared to other similar products (Funk et al. 2015). However, this expedited study does not intend to perform a full intercomparison among various datasets of this type; the intent is to validate IMERG-V04A data using in situ gauge measurements in parts of Africa where this has not been feasible hitherto and to evaluate the performance of the current IMERG version vis-à-vis those of other comparable precipitation datasets. Several other gridded precipitation products that may be used for a more comprehensive intercomparison analysis include Tropical Applications of Meteorology Using Satellite Data and Ground-Based Observations (TAMSAT; Maidment et al. 2014), African Rainfall Climatology (ARC; Novella and Thiaw 2013), PERSIANN-CDR (Ashouri et al. 2015), GPCP (Adler et al. 2003), and CMORPH (Joyce et al. 2004).

\section{Analysis approach}

Gridded data are spatially interpolated to the location of each TAHMO station for comparison. For each application, the mean precipitation rate over its associated interval is used. Annual cycles and probability distribution functions (PDFs) of daily rainfall from various products are compared. The diurnal cycle is examined for three products with subdaily records: TAHMO, IMERG, and TMPA. The TAHMO and IMERG data are averaged over the time range $\pm 90 \mathrm{~min}$ from the nominal 3-hourly observation times used in TMPA. In addition, since IMERG is intended to replace TMPA, the spatial patterns of various evaluation measures of the two products are compared over the entire continent of Africa. These statistics include the correlation coefficient (CC), mean normalized absolute difference (MAD), multiplicative bias (mBias), probability of detection (POD), false alarm ratio (FAR), frequency bias (FBS), critical success index (CSI), and Heidke skill score (HSS). For continent-wide spatial analysis, days with rainfall less than $1 \mathrm{~mm}$ are excluded in calculations of CC, MAD, and mBias. The same threshold is used for categorical indices. For point analysis, a $0.2-\mathrm{mm}$ threshold is applied in order to ensure a sufficient number of dates required for the evaluation process. The definition of validation statistics, described in many references (e.g., Wilks 2011), is provided in the supplemental material using a contingency table (Table S1). Considering reference data $R$ (e.g., in situ observations) and the data that are validated $V$, the POD is the ratio of the correct detection of rain events, FAR is the fraction of the days in $V$ that are wrongly detected as rainy, FBS is the ratio of the number of rainy days in $R$ to the number of rainy days in $V, \mathrm{CSI}$ is an accuracy measure that is particularly useful when the rainy days are substantially less frequent than the no-rain days, and HSS is an accuracy measure that represents the proportion of correct matches between $R$ and $V$ to no-skill random matches.

\section{Intercomparison of gauge and gridded data}

Figures 2-4 show the evaluation results for LPS, Kumasi, and Navrongo, respectively. Various validation measures, calculated for these stations, are provided in Table 1 and in Tables S2 and S3 in the supplemental material. LPS, located in East Africa (Fig. 2), has a bimodal annual cycle of rainfall. The two rainy seasons, occurring during March-May and October-December, are known as "short rains" and "long rains," respectively. TMPA captures the annual cycle relatively better than IMERG, particularly during the short rains when differences are most noticeable among all the products. IMERG provides a better diurnal cycle than TMPA with respect to magnitude and temporal variation. The performance of both products varies by the season with improvements during the long rains (Figs. 2c-e). However, the distribution of daily rainfall intensity provided by IMERG is very similar to that of the gauge observations, as evident in their PDFs and various percentiles (Fig. 2f). The CHIRPS precipitation overall seems to have the largest differences with the gauge data, reflected in the short rains and the extreme daily rainfall rates.

The second TAHMO station, Kumasi (Fig. 3), has also a bimodal annual cycle determined by the meridional excursion of the tropical rain belt (e.g., Dezfuli 2017). Note that this station does not have data available during March and April. Although all products capture the month-to-month variability, some differences are noticeable in the rainfall magnitudes. For example, all gridded data underestimate the rainfall in May, CHIRPS is negatively biased in June, and IMERG presents an overestimation in December. The relatively 

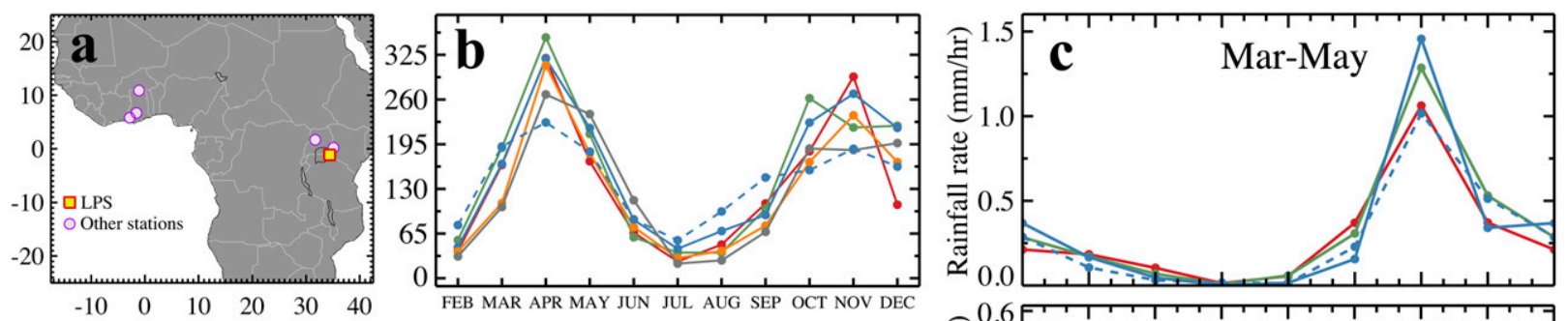

— Gauge — IMERG — TMPA — GPCC —CHIRPS --- TMPA_LTM
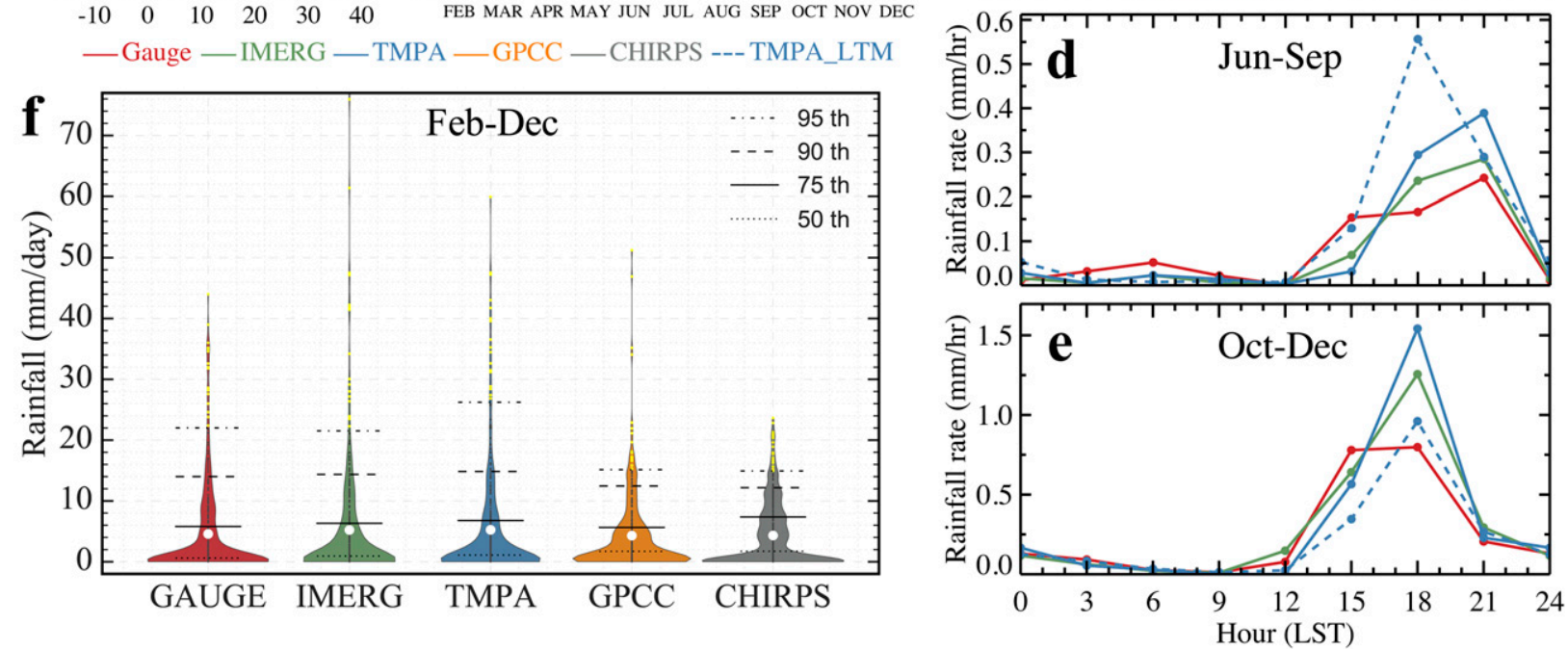

FIG. 2. (a) Location of the station of interest (yellow square), LPS in Kenya, and other stations (purple circles). (b) Annual cycle of rainfall for various datasets during 2015. (c)-(e) Diurnal cycle of rainfall for LPS, IMERG, and TMPA in three different seasons. TMPA_LTM (blue dashed lines), shown in (b)-(e) represents the long-term mean of the annual and diurnal cycles based on TMPA data over 1998-2015. These are used to determine the condition of year 2015 relative to the climatology. (f) PDF of daily rainfall for various datasets; the white circle shows the mean and horizontal lines represent different percentiles. All gridded data are spatially interpolated to the location of the station.

better performance of TMPA compared with IMERG in representing the annual cycle is also reflected in the PDFs, where the 90th and 95th percentiles of TMPA better agree with the in situ observations (Fig. 3f). The diurnal cycle of rainfall, however, is reasonably well captured by both products throughout the year, though IMERG offers some advantages over TMPA during February.

The third TAHMO station used here is Navrongo in northern Ghana (Fig. 4). This station, located in the West African savanna, has a unimodal annual cycle with the peak rainy season occurring during July-September (JAS). Although the annual cycle of various gridded datasets has a good agreement with the in situ observations, IMERG shows a relatively better performance than the others. However, August, which receives the maximum amount of rainfall, is overestimated by all products. The distribution of daily rainfall during April-October (Fig. 4f) is relatively better represented by the TMPA than other datasets, though IMERG's mean intensity is equally close to the gauge data. The GPCC and CHIRPS have very similar PDFs. The diurnal cycle is analyzed over three seasons (May-June, JAS, and October), representing the onset, peak, and cessation of the West African monsoon, respectively. Although the temporal variation of the diurnal cycle is fairly captured, the agreement between in situ and satellite-based observations is less than that shown for the other two stations, and several differences are noticeable. However, important features such as the morning peak (0600 LST) during the JAS rainy season are detected. These rainfall characteristics are consistent with those previously identified over the same region (Fink et al. 2006; Pfeifroth et al. 2016).

Three additional stations are also examined, two in East Africa (Masindi, Uganda, and Kapsabet, Kenya) and one in West Africa (Enchi, Ghana) (Fig. S2). Only diurnal variability of rainfall was investigated using data from these stations, because availability of continuous good-quality records from them was limited to a 2-month period. Enchi shows very good agreement with both the IMERG and TMPA satellite products during the October-November period. The diurnal cycle of the East African stations during the short rains is also reasonably similar to IMERG and TMPA, though some differences are apparent in the temporal variation and magnitude of the rainfall rates. These differences are 

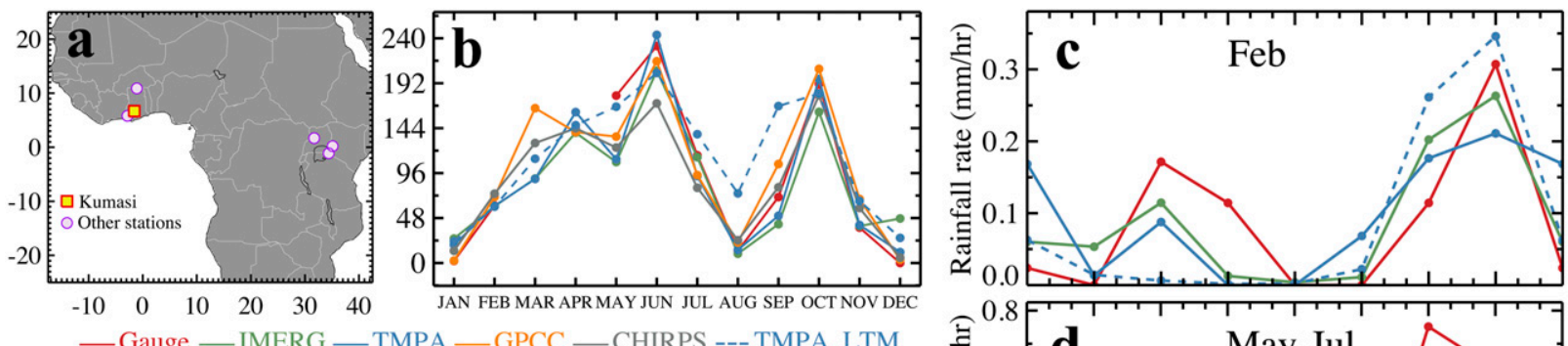

— Gauge — IMERG — TMPA — GPCC — CHIRPS --- TMPA_LTM
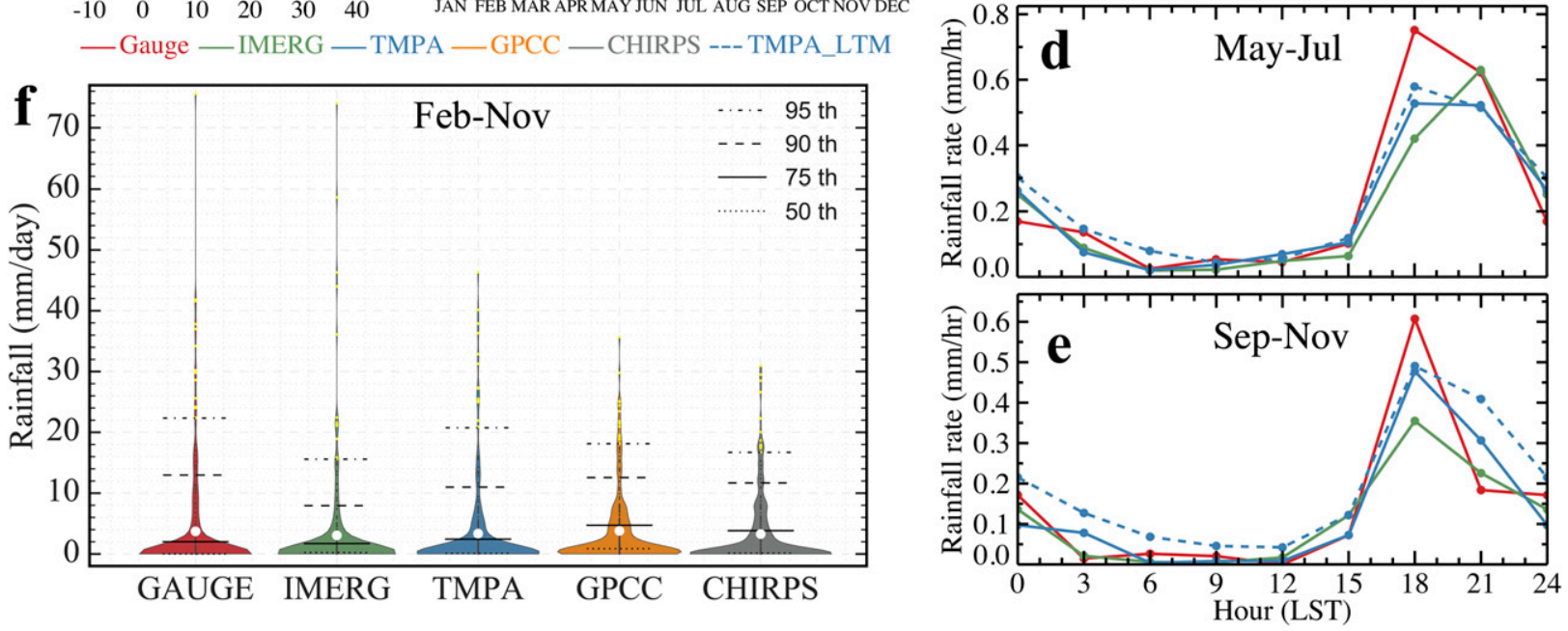

FIG. 3. As in Fig. 2, but for Kumasi, Ghana.

manifested as overestimation by the satellite-based observations, mainly by IMERG at 0300-0600 LST in Masindi and by TMPA at 1800 LST in both stations.

\section{Spatial variability: IMERG versus TMPA}

Various evaluation measures are examined for comparing IMERG and TMPA over the entire continent of Africa (Fig. 5). Each product is also separately compared with the GPCC daily data (Figs. S3 and S4). This allows us to relate the IMERG-TMPA comparison patterns to availability of the GPCC records, used for calibration of these products. Both IMERG and TMPA show generally similar CC patterns with the GPCC. However, except for FAR, TMPA seems to agree with GPCC slightly better than does IMERG. Of all the regions where GPCC records exist, Zimbabwe and Madagascar present the highest agreement with both satellite-based observations, consistent with previous studies (Dinku et al. 2008). Direct comparison between IMERG and TMPA (Fig. 5) reveals that the compatibility between the two products is also regionally heterogeneous and varies by the evaluation measure. Note that IMERG has been treated as the reference data in this comparison. Generally, the two products have their largest differences in most parts of the Horn of Africa and over the Atlas Mountains and the adjacent
Mediterranean coastal area. These areas have the most complex terrain on the continent, so the distribution of gauges, product resolution, and the choice of retrieval algorithms would have a significant impact. These differences are manifested primarily in the spatial patterns of MAD, POD, FBS, CSI, and HSS. These statistics collectively represent the similarity between IMERG and TMPA regarding the mean rainfall rate, detection of rain occurrences, and the accuracy of correct matches relative to that of a no-skill random chance. The regions with the largest differences in temporal variability of the two products, shown in CC patterns, generally appear over the mountainous areas, although this is less evident in Angola and Tanzania. The spatial patterns of CC, POD, FAR, FBS, and CSI show a strong consistency between IMERG and TMPA over the Congo basin and South Sudan. The four categorical statistics measure the agreement in frequency of the daily rain occurrences. However, these regions are located in areas with virtually no GPCC stations, implying that this agreement may not necessarily reflect the quality of satellite observations. The mBias shows remarkably low values over Lake Victoria. Similar results have been found for inland water bodies in China, where IMERG precipitation values much more closely agree with the in situ observations than TMPA (Tang et al. 2016c). This improvement has been attributed to the unified and 

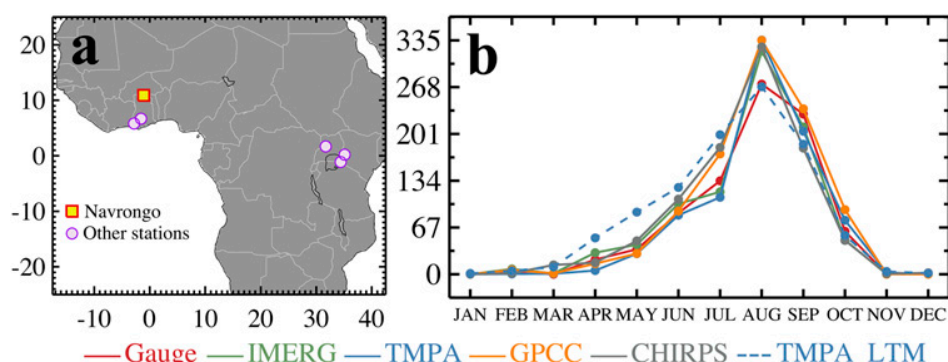

— Gauge — IMERG — TMPA — GPCC —CHIRPS --- TMPA_LTM

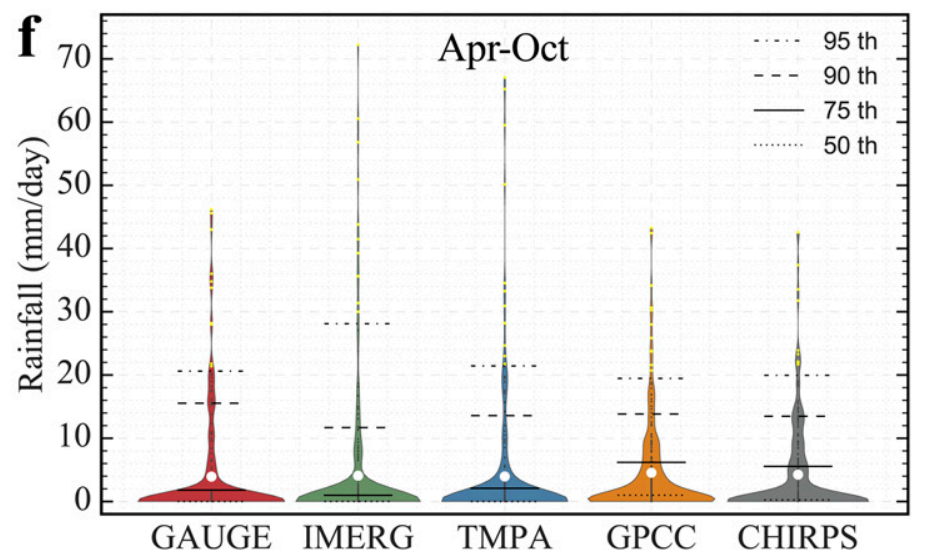

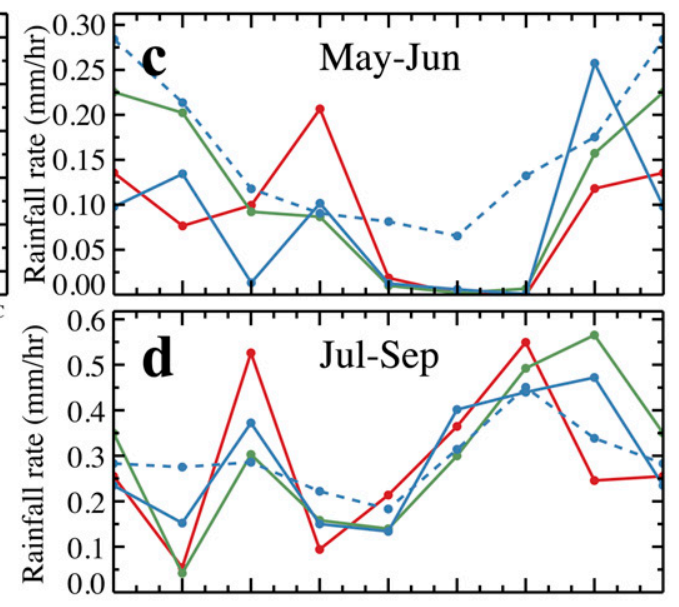

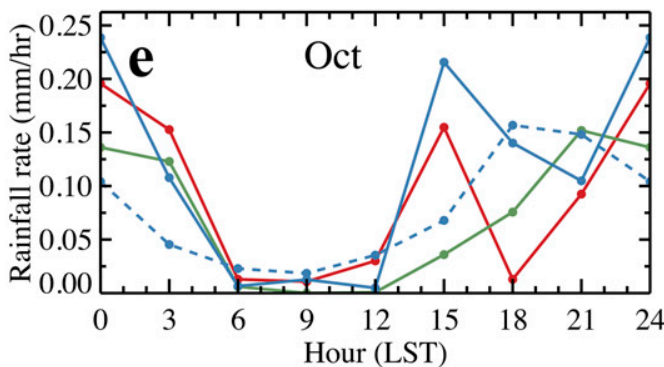

FIG. 4. As in Fig. 2, but for Navrongo, Ghana.

updated passive microwave algorithm used in the GPM products.

\section{Discussion and conclusions}

As a follow-up to our recent work (Dezfuli et al. 2017), we have used data from TAHMO to improve our knowledge about rainfall characteristics in West and East Africa, to validate the IMERG-V04A precipitation data in these regions, and to compare IMERG with its successful predecessor (TMPA) over the African continent. The complete areal coverage of satellite-based observations is vital for capturing the intrinsic spatial heterogeneity of rainfall variability (Dezfuli 2011; Badr et al. 2016) in the data-limited continent of Africa, and this can be further facilitated by the potential of more in situ measurements and ongoing improvements in IMERG. In addition, IMERG can help us better understand the synoptic-scale meteorology of the region, as the western and eastern parts of Africa have been shown to climatically communicate through the regional atmospheric circulation (Dezfuli et al. 2015). The high temporal resolution of in situ and IMERG observations, in particular, has enabled us to better capture the regional variability of subdaily rainfall. The results show that the diurnal cycle has a single peak between 1500 and 2100 LST in East Africa and between 1800 and 2100 LST in southern Ghana. However, the West African savanna

TABLE 1. Evaluation measures based on daily data for IMERG and TMPA at three TAHMO stations for the months in 2015 with available in situ observations. Days with rainfall less than $0.2 \mathrm{~mm}$ are excluded in calculations of CC, MAD, and mBias. The same threshold is used in a contingency table of the categorical statistics (see Table S1). This threshold ensures a sufficient number of dates, as required for the evaluation process.

\begin{tabular}{|c|c|c|c|c|c|c|c|c|c|c|}
\hline Station & Period & Data & $\mathrm{CC}$ & MAD & mBias & POD & FAR & FBS & CSI & $\overline{\mathrm{HSS}}$ \\
\hline \multirow[t]{2}{*}{ LPS, Kenya } & \multirow[t]{2}{*}{ Feb-Dec } & IMERG & 0.54 & 0.81 & 1.04 & 0.84 & 0.17 & 1.02 & 0.71 & 0.58 \\
\hline & & TMPA & 0.55 & 0.83 & 1.08 & 0.81 & 0.20 & 1.01 & 0.68 & 0.53 \\
\hline \multirow[t]{2}{*}{ Kumasi, Ghana } & \multirow[t]{2}{*}{ Feb-Nov } & IMERG & 0.42 & 0.83 & 0.73 & 0.73 & 0.35 & 1.12 & 0.52 & 0.38 \\
\hline & & TMPA & 0.57 & 0.82 & 0.85 & 0.72 & 0.32 & 1.06 & 0.54 & 0.42 \\
\hline \multirow[t]{2}{*}{ Navrongo, Ghana } & \multirow[t]{2}{*}{ Apr-Oct } & IMERG & 0.62 & 0.80 & 1.01 & 0.64 & 0.20 & 0.80 & 0.55 & 0.53 \\
\hline & & TMPA & 0.54 & 0.86 & 0.92 & 0.69 & 0.27 & 0.95 & 0.55 & 0.50 \\
\hline
\end{tabular}



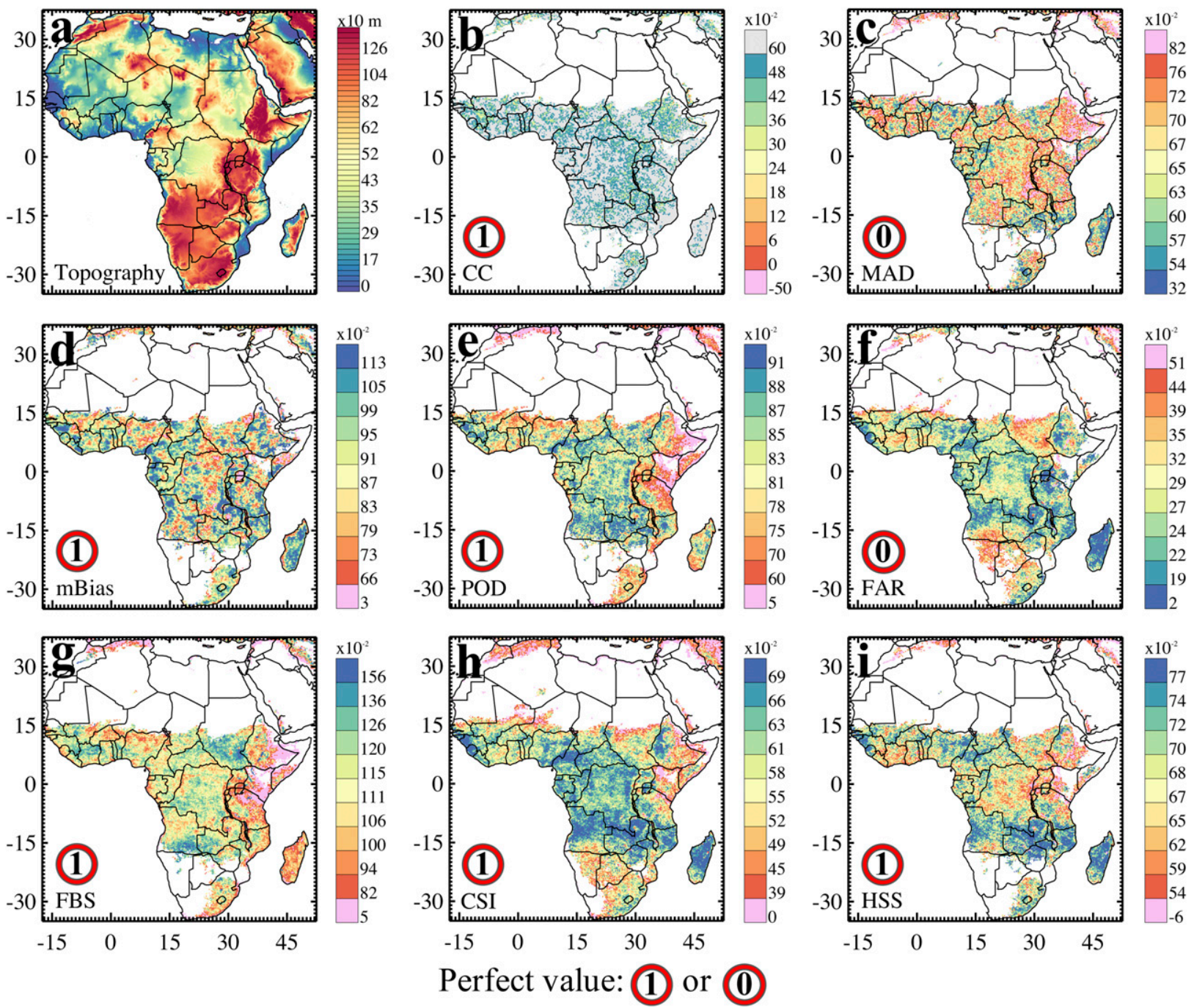

FIG. 5. (a) Topographic map of Africa. (b)-(i) Various validation measures used for comparison between IMERG and TMPA during 2015. IMERG is considered as reference data. Grids with a large number of zero daily rainfall values are masked, using some restricting criteria (see supplemental material).

exhibits a bimodal diurnal cycle that peaks at 0600 and 1800 LST during its rainy season, JAS, consistent with the previous studies over this region (Fink et al. 2006; Pfeifroth et al. 2016).

Although IMERG, partly due to its improved resolution, shows some advantages over TMPA in capturing the diurnal cycle, a clear superiority for other evaluation aspects cannot be claimed. In general, the choice of dataset would depend on the region, season, and objective of study. Various issues have made such decisions quite challenging. That includes the uncertainty due to the comparison of point and gridded datasets in this study, or the fact that we are not able to interpret the good agreement between IMERG and TMPA over the regions with no gauge records available for their calibration (the
Congo basin and South Sudan). In addition, this study is based on one year of data, which does not represent a full range of climate conditions. The growth of the TAHMO network in coming years will hopefully help mitigate these issues and add to available gauge records, with potential usefulness for improving IMERG data that can offer significant contributions to understanding the climate processes in Africa and their implications to the water, agriculture, and health sectors.

Acknowledgments. We thank the three anonymous reviewers for their constructive remarks. A.K.D.'s research was supported by the NASA Postdoctoral Program (NPP) at the Goddard Space Flight Center, administrated by the Universities Space Research Association 
(USRA) through a contract with NASA. This research was also supported under the NASA Research Opportunities in Space and Earth Sciences (ROSES)-2009 and 2013 Interdisciplinary Studies (IDS) Program (Dr. Jack Kaye, Earth Science Research Director), Grant NNH12ZDA001N-IDS, through the Radiation Sciences Program managed by Dr. Hal Maring.

\section{REFERENCES}

Adler, R. F., and Coauthors, 2003: The version-2 Global Precipitation Climatology Project (GPCP) monthly precipitation analysis (1979-present). J. Hydrometeor., 4, 1147-1167, doi:10.1175/1525-7541(2003)004<1147:TVGPCP >2.0.CO;2.

Ashouri, H., K. L. Hsu, S. Sorooshian, D. K. Braithwaite, K. R. Knapp, L. D. Cecil, B. R. Nelson, and O. P. Prat, 2015: PERSIANN-CDR: Daily precipitation climate data record from multisatellite observations for hydrological and climate studies. Bull. Amer. Meteor. Soc., 96, 69-83, doi:10.1175/ BAMS-D-13-00068.1.

Asong, Z. E., S. Razavi, H. S. Wheater, and J. S. Wong, 2017: Evaluation of Integrated Multisatellite Retrievals for GPM (IMERG) over southern Canada against ground precipitation observations: A preliminary assessment. J. Hydrometeor., 18, 1033-1050, doi:10.1175/JHM-D-16-0187.1.

Badr, H. S., A. K. Dezfuli, B. F. Zaitchik, and C. D. Peters-Lidard, 2016: Regionalizing Africa: Patterns of precipitation variability in observations and global climate models. J. Climate, 29, 9027-9043, doi:10.1175/JCLI-D-16-0182.1.

Beighley, R. E., and Coauthors, 2011: Comparing satellite derived precipitation datasets using the Hillslope River Routing (HRR) model in the Congo River Basin. Hydrol. Processes, 25, 3216-3229, doi:10.1002/hyp.8045.

Dezfuli, A. K., 2011: Spatio-temporal variability of seasonal rainfall in western equatorial Africa. Theor. Appl. Climatol., 104, 57-69, doi:10.1007/s00704-010-0321-8.

2017: Climate of western and central equatorial Africa. Oxford Research Encyclopedia of Climate Science, 66 pp., doi:10.1093/acrefore/9780190228620.013.511.

— the African easterly jet. Int. J. Climatol., 31, 2049-2054, doi:10.1002/joc.2209.

— western equatorial Africa to the tropical oceans and atmospheric circulation. Part II: The boreal autumn. J. Climate, 26, 66-84, doi:10.1175/JCLI-D-11-00686.1.

— B. F. Zaitchik, and A. Gnanadesikan, 2015: Regional atmospheric circulation and rainfall variability in south equatorial Africa. J. Climate, 28, 809-818, doi:10.1175/JCLI-D-14-00333.1.

—, C. M. Ichoku, K. Mohr, and G. J. Huffman, 2017: Precipitation characteristics in West and East Africa from satellite and in situ observations. J. Hydrometeor., 18, 1799-1805, doi:10.1175/JHM-D-17-0068.1.

Dinku, T., S. Chidzambwa, P. Ceccato, S. J. Connor, and C. F. Ropelewski, 2008: Validation of high-resolution satellite rainfall products over complex terrain. Int. J. Remote Sens., 29, 4097-4110, doi:10.1080/01431160701772526.

Fink, A. H., D. G. Vincent, and V. Ermert, 2006: Rainfall types in the West African Sudanian zone during the summer monsoon 2002. Mon. Wea. Rev., 134, 2143-2164, doi:10.1175/ MWR3182.1.
Funk, C., and Coauthors, 2015: The climate hazards infrared precipitation with stations-a new environmental record for monitoring extremes. Sci. Data, 2, 150066, doi:10.1038/sdata.2015.66.

Hill, P. G., R. P. Allan, J. C. Chiu, and T. H. Stein, 2016: A multisatellite climatology of clouds, radiation, and precipitation in southern West Africa and comparison to climate models. J. Geophys. Res. Atmos., 121, $10857-10879$, doi:10.1002/ 2016JD025246.

Huffman, G. J., D. T. Bolvin, and E. J. Nelkin, 2015: Day 1 IMERG final run release notes. NASA Doc., 9 pp., https://pmm.nasa.gov/ sites/default/files/document_files/IMERG_FinalRun_Day1_ release_notes.pdf.

Ichoku, C., and Coauthors, 2016: Biomass burning, land-cover change, and the hydrological cycle in northern sub-Saharan Africa. Environ. Res. Lett., 11, 095005, doi:10.1088/1748-9326/ 11/9/095005.

Joyce, R. J., J. E. Janowiak, P. A. Arkin, and P. Xie, 2004: CMORPH: A method that produces global precipitation estimates from passive microwave and infrared data at high spatial and temporal resolution. J. Hydrometeor., 5, 487-503, doi:10.1175/1525-7541(2004)005<0487:CAMTPG >2.0.CO;2.

Kiladis, G. N., C. D. Thorncroft, and N. M. Hall, 2006: Threedimensional structure and dynamics of African easterly waves. Part I: Observations. J. Atmos. Sci., 63, 2212-2230, doi:10.1175/JAS3741.1.

Lawrence, D., and K. Vandecar, 2015: Effects of tropical deforestation on climate and agriculture. Nat. Climate Change, $\mathbf{5}$, 27-36, doi:10.1038/nclimate2430.

Liu, Z., 2016: Comparison of Integrated Multisatellite Retrievals for GPM (IMERG) and TRMM Multisatellite Precipitation Analysis (TMPA) monthly precipitation products: Initial results. J. Hydrometeor., 17, 777-790, doi:10.1175/JHM-D-15-0068.1.

Ma, Y., G. Tang, D. Long, B. Yong, L. Zhong, W. Wan, and Y. Hong, 2016: Similarity and error intercomparison of the GPM and its predecessor-TRMM Multisatellite Precipitation Analysis using the best available hourly gauge network over the Tibetan Plateau. Remote Sens., 8, 569, doi:10.3390/rs8070569.

Maidment, R. I., D. Grimes, R. P. Allan, E. Tarnavsky, M. Stringer, T. Hewison, R. Roebeling, and E. Black, 2014: The 30 year TAMSAT African Rainfall Climatology and Time Series (TARCAT) data set. J. Geophys. Res. Atmos., 119, 10619 10644 doi:10.1002/2014JD021927.

Munzimi, Y. A., M. C. Hansen, B. Adusei, and G. B. Senay, 2015: Characterizing Congo basin rainfall and climate using Tropical Rainfall Measuring Mission (TRMM) satellite data and limited rain gauge ground observations. J. Appl. Meteor. Climatol., 54, 541-555, doi:10.1175/JAMC-D-14-0052.1.

Naumann, G., P. Barbosa, H. Carrao, A. Singleton, and J. Vogt, 2012: Monitoring drought conditions and their uncertainties in Africa using TRMM data.J. Appl. Meteor. Climatol., 51, 18671874, doi:10.1175/JAMC-D-12-0113.1.

Novella, N. S., and W. M. Thiaw, 2013: African rainfall climatology version 2 for famine early warning systems. J. Appl. Meteor. Climatol., 52, 588-606, doi:10.1175/JAMC-D-11-0238.1.

Oliveira, R., V. Maggioni, D. Vila, and C. Morales, 2016: Characteristics and diurnal cycle of GPM rainfall estimates over the central Amazon region. Remote Sens., 8, 544, doi:10.3390/rs8070544.

Pfeifroth, U., J. Trentmann, A. H. Fink, and B. Ahrens, 2016: Evaluating satellite-based diurnal cycles of precipitation in the African tropics. J. Appl. Meteor. Climatol., 55, 23-39, doi:10.1175/JAMC-D-15-0065.1.

Prakash, S., A. K. Mitra, D. S. Pai, and A. AghaKouchak, 2016: From TRMM to GPM: How well can heavy rainfall be 
detected from space? Adv. Water Resour., 88,1-7, doi:10.1016/ j.advwatres.2015.11.008.

Rivero-Calle, S., C. E. Del Castillo, A. Gnanadesikan, A. Dezfuli, B. Zaitchik, and D. G. Johns, 2016: Interdecadal Trichodesmium variability in cold North Atlantic waters. Global Biogeochem. Cycles, 30, 1620-1638, doi:10.1002/2015GB005361.

Sahlu, D., E. I. Nikolopoulos, S. A. Moges, E. N. Anagnostou, and D. Hailu, 2016: First evaluation of the Day-1 IMERG over the upper Blue Nile basin. J. Hydrometeor., 17, 2875-2882, doi:10.1175/JHM-D-15-0230.1.

Schamm, K., M. Ziese, A. Becker, P. Finger, A. Meyer-Christoffer, U. Schneider, M. Schröder, and P. Stender, 2014: Global gridded precipitation over land: A description of the new GPCC First Guess Daily product. Earth Syst. Sci. Data, 6 , 49-60, doi:10.5194/essd-6-49-2014.

Sharifi, E., R. Steinacker, and B. Saghafian, 2016: Assessment of GPM-IMERG and other precipitation products against gauge data under different topographic and climatic conditions in Iran: Preliminary results. Remote Sens., 8, 135, doi:10.3390/rs8020135.

Swap, R., M. Garstang, S. Greco, R. Talbot, and P. Kållberg, 1992: Saharan dust in the Amazon Basin. Tellus, 44B, 133-149, doi:10.3402/tellusb.v44i2.15434.

Tan, J., W. A. Petersen, and A. Tokay, 2016: A novel approach to identify sources of errors in IMERG for GPM ground validation. J. Hydrometeor., 17, 2477-2491, doi:10.1175/ JHM-D-16-0079.1.

Tang, G., Y. Ma, D. Long, L. Zhong, and Y. Hong, 2016a: Evaluation of GPM Day-1 IMERG and TMPA version-7 legacy products over mainland China at multiple spatiotemporal scales. J. Hydrol., 533, 152-167, doi:10.1016/ j.jhydrol.2015.12.008.

, Z. Zeng, D. Long, X. Guo, B. Yong, W. Zhang, and Y. Hong, 2016b: Statistical and hydrological comparisons between TRMM and GPM level-3 products over a midlatitude basin: Is Day-1 IMERG a good successor for TMPA 3B42V7? J. Hydrometeor., 17, 121-137, doi:10.1175/ JHM-D-15-0059.1.

D. Long, and Y. Hong, 2016c: Systematic anomalies over inland water bodies of High Mountain Asia in TRMM precipitation estimates: No longer a problem for the GPM era? IEEE Geosci. Remote Sens. Lett., 13, 1762-1766, doi:10.1109/ LGRS.2016.2606769.

Van de Giesen, N., R. Hut, and J. Selker, 2014: The Trans-African Hydro-Meteorological Observatory (TAHMO). Wiley Interdiscip. Rev.: Water, 1, 341-348, doi:10.1002/wat2.1034.

Wilks, D. S., 2011: Statistical Methods in the Atmospheric Sciences. 3rd ed. International Geophysics Series, Vol. 100, Academic Press, 704 pp. 